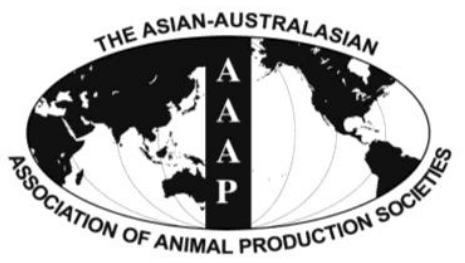

Asian-Aust. J. Anim. Sci.

Vol. 25, No. 12 : 1667-1673 December 2012

http://dx.doi.org/10.5713/ajas.2012.12397

www.ajas.info

pISSN 1011-2367 elSSN 1976-5517

\title{
Estimation of Relative Economic Weights of Hanwoo Carcass Traits Based on Carcass Market Price
}

\author{
Yun Ho Choy*, Byoung Ho Park, Tae Jung Choi, Jae Gwan Choi, Kwang Hyun Cho, \\ Seung Soo Lee, You Lim Choi, Kyung Chul Koh ${ }^{1}$ and Hyo Sun Kim ${ }^{1}$ \\ Animal Breeding and Genetics Division, National Institute of Animal Science, Chonan 330-801, Korea
}

\begin{abstract}
The objective of this study was to estimate economic weights of Hanwoo carcass traits that can be used to build economic selection indexes for selection of seedstocks. Data from carcass measures for determining beef yield and quality grades were collected and provided by the Korean Institute for Animal Products Quality Evaluation (KAPE). Out of 1,556,971 records, 476,430 records collected from 13 abattoirs from 2008 to 2010 after deletion of outlying observations were used to estimate relative economic weights of bid price per kg carcass weight on cold carcass weight (CW), eye muscle area (EMA), backfat thickness (BF) and marbling score (MS) and the phenotypic relationships among component traits. Price of carcass tended to increase linearly as yield grades or quality grades, in marginal or in combination, increased. Partial regression coefficients for MS, EMA, BF, and for CW in original scales were +948.5 won $/ \mathrm{score},+27.3$ won $/ \mathrm{cm}^{2},-95.2 \mathrm{won} / \mathrm{mm}$ and +7.3 won $/ \mathrm{kg}$ when all three sex categories were taken into account. Among four grade determining traits, relative economic weight of MS was the greatest. Variations in partial regression coefficients by sex categories were great but the trends in relative weights for each carcass measures were similar. Relative economic weights of four traits in integer values when standardized measures were fit into covariance model were $+4:+1:-1:+1$ for MS:EMA:BF:CW. Further research is required to account for the cost of production per unit carcass weight or per unit production under different economic situations. (Key Words: Hanwoo, Selection Index, Economic Weight, Carcass Trait)
\end{abstract}

\section{INTRODUCTION}

Hanwoo (Korean native beef cattle breed) breeding in Korea is managed by the Korean government. Performance testing of bull calves from Hanwoo breeder farms is made at the Hanwoo Improvement Center (HIC) of the Agricultural Cooperative located Seosan, Korea. Progeny borne from performance tested young bulls are made also at HIC until they are castrated and fed to slaughter at around 24 months of age. Carcass traits that determine the yield and quality grade are the major selection criteria to finally select bulls for semen distribution country-wide. This performance testing with progeny testing program is run twice every year for the total of 300 bull calves a year.

In case beef cattle sale price after slaughter is of top concern for feedlot operators, carcass price on free auction that depends on yield or quality grades will be the direct

\footnotetext{
* Corresponding Author: Yun Ho Choy. Tel: +82-41-580-3354, Fax: +82-41-582-1248, E-mail: ychoy000@korea.kr

${ }^{1}$ Korea Institute for Animal Products Quality Evaluation, Dangdong 424-6, Gunpo 435-010, Korea.

Submitted Jul. 4, 2012; Accepted Sept. 4, 2012; Revised Sept. 15, 2012
}

expression of the profit difference for producers. The major components that determine the carcass grades are backfat thickness, eye muscle area and cold carcass weight for yield grade and intramuscular fat percentage or marbling score for quality grade under the Korean Beef Grading Standards. Considerable effort to select Hanwoo bulls based on genetic parameter estimation of carcass traits has been made (Lee et al., 2000; Baik et al., 2003; Choy et al., 2008). But analyses of breeding objectives with consideration of carcass price values were little (Kim et al., 2010). Recently, a few studies on Japanese beef cattle attempted to estimate economic weights for carcass traits directly from carcass price (Ibi et al., 2006; Kahi et al., 2007) following the methods used for dairy cattle (Visscher and Goddard, 1995; Perez-Cabal and Alenda, 2002; 2003) rather than estimating economic weights of component goal traits and combining them into selection indexes. However, beef carcass price fluctuates over seasons and years of production more drastically than does milk price. Cost of production also changes yearly due to global oil price changes and subsequent international grain supply chain shifts, which makes prediction of consistent beef carcass prices quite complex even in the 
near future. Therefore, estimation of carcass price changes per unit carcass weight over a short time interval is desirable to make selection decisions for future beef carcass market compared to the case of rather steady milk price.

The objective of this study was to estimate economic weights for carcass traits dependent on chilled carcass price by grades at auction. Economic weights on component traits (cold carcass weight, backfat thickness, eye muscle area and marbling score) were estimated to be used for selection index targeting higher yield and quality grade of beef carcass.

\section{MATERIALS AND METHODS}

\section{Data}

Hanwoo carcass auction prices by three sex categories ( 1 = female, 2 = bull, 3 = steer) and by carcass quality and yield grades were used for estimation of economic weights of carcass traits. Data were collected by the Korean Institute for Animal Products Quality Evaluation (KAPE) for Hanwoo cattle that were slaughtered at 13 abattoirs from 2008 to 2010. Of total records of 1,556,971 head, records of 476,430 head were finally selected. These data sets were the observation of carcass price of at least 6,000 wons $/ \mathrm{kg}$ $(1,200$ wons are approximately equivalent to US\$1.00) with carcass grades assessed over grade D (failure to pass). The range of data retained after cutting off outliers were: backfat thickness greater than $1 \mathrm{~mm}$, female carcass $(35 \leq \mathrm{EMA}<170$ $\mathrm{cm}^{2}$, BF less than $90 \mathrm{~mm}, 150 \leq \mathrm{CW}<450 \mathrm{~kg}$ ), bull carcass $\left(35 \leq \mathrm{EMA}<140 \mathrm{~cm}^{2}, \quad \mathrm{CW} \leq 660 \mathrm{~kg}\right)$ and steer carcass $\left(\right.$ EMA $\leq 200 \mathrm{~cm}^{2}, \mathrm{BF} \leq 90 \mathrm{~mm}, 220 \leq \mathrm{CW} \leq 650 \mathrm{~kg}$ ). Carcass traits considered in this study were cold carcass weight $(\mathrm{CW}, \mathrm{kg})$, eye muscle area $\left(\mathrm{EMA}, \mathrm{cm}^{2}\right)$, backfat thickness $(\mathrm{BF}, \mathrm{mm})$ and marbling score $(\mathrm{MS}, 1$ to $9,1=$ no intramuscular fat, 9 = extremely abundant in intramuscular fat). Those who want more information about Korean beef grading standards, refer to Choy et al. (2010).

\section{Economic weight estimation}

Generalized linear covariance models were fit to estimate the partial regression of carcass price at auction to various carcass traits that determine the yield or quality grades.

Model 1 (all sex categories):

$\mathrm{y}=\mathrm{b}_{0}+$ sex $\times$ house $+\mathrm{b}_{1}(\mathrm{MS})+\mathrm{b}_{2}($ EMA $)$

$$
+b_{3}(B F)+b_{4}(C W)+e
$$

Model 2 (by sex categories):

$\mathrm{y}=\mathrm{b}_{0}+$ house $+\mathrm{b}_{1}(\mathrm{MS})+\mathrm{b}_{2}(\mathrm{EMA})+\mathrm{b}_{3}(\mathrm{BF})+\mathrm{b}_{4}(\mathrm{CW})+\mathrm{e}$

Here, y is carcass price (won, W) assessed by half carcass buyers at auction. House is the effect of abattoirs, which was a significant source of variation in interaction with sex categories (Model 1) as well as solely in all sex categories (Model 2). Covariates were the carcass measures (MS, EMA, BF, CW) with regression coefficients $\left(b_{0}, b_{1}, b_{2}\right.$, $b_{3}, b_{4}$ ) associated with each covariate. Sex categories and houses were fit in interaction terms because carcass bid price is rather dependent on abattoirs first and differences among sex categories are secondly dependent on auctioneers participating in each abattoir.

Multivariate effect model to estimate phenotypic (co)variances and phenotypic correlation coefficients among carcass traits was as follows.

$$
\mathrm{Y}=\mathrm{XB}+\mathrm{R}
$$

Where, $\mathrm{Y}$ is the observation matrix consisting of four carcass measures (MS, EMA, BF, CW). B is a solution matrix consisted of overall means for each variable in $\mathrm{Y}$, three sex categories, thirteen abattoirs (house) and interaction terms between these two effects. $\mathrm{X}$ is a matrix associated with levels in $\mathrm{B}$, and $\mathrm{R}$ is a matrix of residuals. In case the models were fit separately for each sex category, effect of sex and the interaction effect between sexes and abattoirs were excluded from B.

Standard measures to fit the models were used as well to account for differences in scales by traits. Original observed measures were standardized for means and standard deviations of censored data set by traits. Means and SD's applied to standardization were $4.46 \pm 2.23$ (score) for MS, $83.03 \pm 12.23 \mathrm{~cm}^{2}$ for EMA, $12.51 \pm 5.87 \mathrm{~mm}$ for BF and $368.18 \pm 67.54 \mathrm{~kg}$ for $\mathrm{CW}$.

Multivariate analyses were also made by generalized linear model (GLM) procedure of SAS (2010) with manova (multivariate analysis of variance) option (Johnson and Wichern, 1992).

\section{RESULTS AND DISCUSSION}

Table 1 summarizes the bid price structure of Hanwoo carcasses put to auction after overnight chilling postslaughter. Numbers of observations were defined by the total number of carcasses in the data set and the total number of carcasses with bid prices. The difference in numbers between these two is the number of carcasses sold to whole sellers before slaughter. Original bid price range was too great to account for real purchase willingness of the buyers. Therefore, data were selected primarily not to include carcasses with grade ' $\mathrm{D}$ ' which can be regarded as of little value. The carcasses priced less than 6,000 wons $/ \mathrm{kg}$ can also be regarded as those carcasses with some defects such that buyers may be reluctant to buy at a normal price. Table 2 summarizes the bid price statistics of the carcasses after deletion of outlying observations, the data of which 
Table 1. Average bid price of the Hanwoo carcasses (won/kg) by final grades

\begin{tabular}{|c|c|c|c|c|c|c|}
\hline \multirow{2}{*}{ Grade } & \multirow{2}{*}{$\mathrm{N}$ (slaughtered) } & \multirow{2}{*}{$\mathrm{N}$ (with bid price) } & \multicolumn{4}{|c|}{ Price (won/kg carcass) } \\
\hline & & & Average & SD & Min & Max \\
\hline $1++\mathrm{A}$ & 36,612 & 11,344 & 20,402 & 1,792 & 9,012 & 41,538 \\
\hline $1++B$ & 71,258 & 22,248 & 19,873 & 1,998 & 9,000 & 37,000 \\
\hline $1++\mathrm{C}$ & 23,852 & 10,258 & 18,695 & 1,906 & 10,000 & 30,510 \\
\hline $1+\mathrm{A}$ & 82,948 & 26,341 & 18,189 & 1,591 & 5,199 & 26,100 \\
\hline $1+\mathrm{B}$ & 179,519 & 55,326 & 17,647 & 1,785 & 201 & 26,930 \\
\hline $1+\mathrm{C}$ & 52,231 & 20,826 & 16,445 & 1,748 & 5,000 & 25,390 \\
\hline $1 \mathrm{~A}$ & 111,582 & 33,582 & 16,687 & 1,726 & 1,000 & 24,890 \\
\hline 1B & 252,093 & 78,799 & 16,008 & 1,925 & 1,000 & 27,890 \\
\hline $1 \mathrm{C}$ & 70,672 & 29,469 & 14,953 & 1,990 & 4,899 & 25,860 \\
\hline $2 \mathrm{~A}$ & 133,464 & 35,461 & 14,228 & 1,996 & 1,200 & 20,259 \\
\hline $2 \mathrm{~B}$ & 208,262 & 65,936 & 13,272 & 2,066 & 294 & 19,816 \\
\hline $2 \mathrm{C}$ & 48,752 & 20,481 & 12,290 & 2,017 & 1,000 & 18,890 \\
\hline $3 \mathrm{~A}$ & 182,271 & 33,872 & 11,381 & 2,284 & 1,000 & 19,175 \\
\hline $3 \mathrm{~B}$ & 74,695 & 27,514 & 10,159 & 2,122 & 100 & 18,450 \\
\hline $3 \mathrm{C}$ & 17,159 & 8,765 & 9,022 & 2,195 & 100 & 15,562 \\
\hline D & 11,601 & 9,254 & 4,805 & 2,623 & 10 & 15,077 \\
\hline Overall & $1,556,971$ & 489,476 & $14,628.50$ & & & \\
\hline
\end{tabular}

were used to estimate economic weights for carcass characteristics.

There was tendency to increase the carcass price by around 780 wons $/ \mathrm{kg}$ as quality and yield grades in combination increased to more retail beef yielding and higher quality carcasses.

Distribution of backfat thickness of the female carcasses observed tended to be skewed to the right. Log transformation of backfat thickness improved normality. However, when 10 to 90 percentile of the data were selected, distributions of $\mathrm{BF}$ in the original (untransformed) scale were quite normal except for bull carcasses. Most of these carcasses falling within the lower $10 \%$ had backfat thickness of only $1 \mathrm{~mm}$. Female carcasses were mostly from old cows mostly around 5 to 7 yrs of age but the information about the exact age to confirm this was not available. The grades would diverge greatly depending on whether the process of fattening occurred before they were sent to slaughter houses. There are also some possibilities that young heifers were included as female carcasses. Bull carcasses might have had similar age structure as female carcasses.

Table 2. Average bid price of the Hanwoo carcasses (won $/ \mathrm{kg}$ ) by final grades without grade 'D' and with price over won $6,000 / \mathrm{kg}$

\begin{tabular}{|c|c|c|c|c|c|}
\hline \multirow{2}{*}{ Grade } & \multirow{2}{*}{$\mathrm{N}$} & \multicolumn{4}{|c|}{ Price (won/kg carcass) } \\
\hline & & Average & SD & Min & Max \\
\hline & & ---------- & ing outlier & rcass me & - \\
\hline $1++\mathrm{A}$ & 11,339 & $20,401.8$ & $1,791.3$ & 9,012 & 41,538 \\
\hline $1++B$ & 22,218 & $19,872.3$ & $1,996.7$ & 9,000 & 37,000 \\
\hline $1++\mathrm{C}$ & 10,205 & $18,689.7$ & $1,899.6$ & 10,000 & 30,510 \\
\hline $1+\mathrm{A}$ & 26,326 & $18,190.3$ & $1,585.5$ & 7,500 & 26,100 \\
\hline $1+\mathrm{B}$ & 55,266 & $17,648.3$ & $1,782.6$ & 7,550 & 26,930 \\
\hline $1+\mathrm{C}$ & 20,738 & $16,448.2$ & $1,742.8$ & 8,100 & 25,390 \\
\hline $1 \mathrm{~A}$ & 33,557 & $16,689.1$ & $1,719.3$ & 6,500 & 24,890 \\
\hline 1B & 78,677 & $16,010.9$ & $1,919.9$ & 6,500 & 27,890 \\
\hline $1 \mathrm{C}$ & 29,281 & $14,959.5$ & $1,980.8$ & 6,000 & 25,860 \\
\hline $2 \mathrm{~A}$ & 35,444 & $14,228.8$ & $1,994.7$ & 6,000 & 20,259 \\
\hline $2 \mathrm{~B}$ & 65,778 & $13,279.6$ & $2,052.0$ & 6,000 & 19,816 \\
\hline $2 \mathrm{C}$ & 20,174 & $12,327.9$ & $1,974.3$ & 6,000 & 18,890 \\
\hline $3 \mathrm{~A}$ & 33,805 & $11,386.4$ & $2,276.5$ & 6,000 & 19,175 \\
\hline $3 \mathrm{~B}$ & 26,625 & $10,252.9$ & $2,039.9$ & 6,000 & 18,450 \\
\hline $3 C$ & 6,997 & $9,405.1$ & 1,936 & 6,000 & 15,562 \\
\hline Overall & 476,430 & $15,319.4$ & & & \\
\hline
\end{tabular}


Effects of sex categories and abattoirs were a significant source of variation of carcass bid prices. Table 3 shows the phenotypic variance and covariances estimated for the carcass traits as the effects of sex categories and abattoirs were controlled from observed measures.

Phenotypic variances of MS, EMA, BF or CW, the latter three of which are the determinants of carcass yield grade, were not greatly changed in censored data sets in the models composing all sex categories. The phenotypic covariances among these were not changed either. But the correlation between MS and yield grade determining traits became somewhat higher by deleting outliers. EMA was highly correlated with $\mathrm{CW}$ but was lowly correlated with BF. MS was moderately correlated with EMA but was lowly correlated with BF. Of all three sex categories, variance-covariance structures among carcass traits were quite different in the bull data set (Table 3). Phenotypic variance in $\mathrm{CW}$ was increased by about $1 / 4$ compared to that of the other two sex categories while phenotypic variances in MS, BF were greatly decreased. And the variation in MS was more highly correlated with variation in $\mathrm{BF}$ and less correlated with variations in EMA or CW.
Phenotypic correlation between $\mathrm{BF}$ and $\mathrm{CW}$ was less in the bull data set than in the steer or female data set. This might be due to the fact that bulls have greater variation in their feeding before they are sent to slaughter houses. Therefore, fattening procedure would have great effect on backfat deposition and later on intramuscular fat deposition (MS). Some or most of bulls or old cows are sent to slaughter houses without proper fattening procedure after the culling decision has been made by their owners. Phenotypic variances estimated in this study for four carcass traits were similar to those estimated in a Hanwoo herd at Hanwoo Experiment Station of the National Institute of Animal Science (NIAS) with three different slaughter end points: age at slaughter as linear and quadratic covariates, body weight at slaughter, and both (Choy et al., 2008). However, phenotypic variance estimates of MS, BF or EMA were much greater than those estimated by Lee et al. (2000). This difference might be due to the fact that the data set used by Lee et al. (2000) was only for bulls or steers that were performance tested at test stations with common feeding and under the same slaughtering environments compared to the data set of this study that came from commercial farm

Table 3. Phenotypic variances $\left(\sigma_{p}^{2}\right.$, diagonals), covariances $\left(\sigma_{\mathrm{p} 12}\right.$, below diagonals) and correlation coefficients ( $\mathrm{r}_{\mathrm{p} 12}$, above diagonals) estimated between carcass traits ${ }^{1}$

\begin{tabular}{|c|c|c|c|c|}
\hline \multirow{2}{*}{$\sigma_{\mathrm{p} 12} / \sigma_{\mathrm{p}}^{2} / \mathrm{r}_{\mathrm{p} 12}$} & \multicolumn{4}{|c|}{ Carcass traits $^{2}$} \\
\hline & MS & EMA & $\mathrm{BF}$ & $\mathrm{CW}$ \\
\hline & 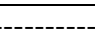 & - All the & $\mathrm{r} \mathrm{df}=1$, & 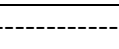 \\
\hline MS & 3.53 & 0.25 & 0.13 & 0.19 \\
\hline EMA & 4.75 & 105.90 & 0.11 & 0.62 \\
\hline $\mathrm{BF}$ & 1.17 & 5.28 & 23.74 & 0.35 \\
\hline \multirow[t]{2}{*}{$\mathrm{CW}$} & 16.48 & 293.99 & 77.86 & $2,108.44$ \\
\hline & \multicolumn{4}{|c|}{ All sexes $($ Error $\mathrm{df}=476,391)$} \\
\hline MS & 3.82 & 0.32 & 0.16 & 0.25 \\
\hline EMA & 6.74 & 116.95 & 0.13 & 0.64 \\
\hline $\mathrm{BF}$ & 1.64 & 7.58 & 28.90 & 0.39 \\
\hline \multirow[t]{2}{*}{$\mathrm{CW}$} & 23.17 & 330.58 & 100.55 & $2,303.09$ \\
\hline & \multicolumn{4}{|c|}{ Sex $=$ Female $($ Error $\mathrm{df}=195,027)$} \\
\hline MS & 3.96 & 0.30 & 0.19 & 0.31 \\
\hline EMA & 6.90 & 133.04 & 0.17 & 0.72 \\
\hline $\mathrm{BF}$ & 2.22 & 11.34 & 33.19 & 0.36 \\
\hline \multirow[t]{2}{*}{$\mathrm{CW}$} & 28.37 & 383.40 & 96.52 & $2,155.36$ \\
\hline & \multicolumn{4}{|c|}{ Sex $=$ Bull $($ Error $\mathrm{df}=38,248)$} \\
\hline MS & 0.55 & 0.05 & 0.32 & 0.12 \\
\hline EMA & 0.43 & 129.39 & 0.12 & 0.69 \\
\hline $\mathrm{BF}$ & 0.66 & 3.79 & 7.39 & 0.28 \\
\hline \multirow[t]{2}{*}{$\mathrm{CW}$} & 4.72 & 413.73 & 40.49 & $2,776.53$ \\
\hline & \multicolumn{4}{|c|}{ Sex $=$ Steer $($ Error $\mathrm{df}=243,116)$} \\
\hline MS & 4.22 & 0.37 & 0.12 & 0.22 \\
\hline EMA & 7.61 & 102.08 & 0.10 & 0.56 \\
\hline $\mathrm{BF}$ & 1.34 & 5.17 & 28.84 & 0.44 \\
\hline $\mathrm{CW}$ & 21.90 & 275.12 & 113.23 & $2,347.12$ \\
\hline
\end{tabular}

${ }^{1}$ Prices less than 6,000/kg and of final grade 'D's were excluded.

${ }^{2} \mathrm{MS}=$ Marbling score (1 to 9), EMA $=$ Eye muscle area $\left(\mathrm{cm}^{2}\right), \mathrm{BF}=$ Backfat thickness (mm), $\mathrm{CW}=$ Carcass weight $(\mathrm{kg})$. 
environments with various slaughtering conditions, especially the age variation of cows or bulls at slaughter. Consequently, with only steer carcass observations the differences among study results were similar. This suggests the importance of environmental variation in prediction of genetic potentials of animals on carcass traits when different sources of data were considered.

Phenotypic correlation coefficients estimated in this study were similar but somewhat higher than those estimated by Kim et al. (2010), the data of which were only for cows fed and slaughtered in one region in Korea.

Table 4 shows the estimated economic weights of carcass traits of all sex categories as well as those by each sex category in terms of regression coefficients of carcass bid price per $\mathrm{kg}$ weight on each carcass trait measures. Economic weights of MS were the greatest in all sex categories as well as in each sex category. And those of BF were the next most important. Those of EMA or CW were the least important of all four carcass measures. This must be due to the fact that the quality grade of beef carcass is mostly determined by MS while yield grade is determined by the combination of BF, EMA and CW. Moreover, of the latter three traits, $\mathrm{BF}$ is the most important measure in determination of beef carcass yield grade. Compared to the weight on all sex categories, the changes in unit carcass price by unit changes in MS of female or bull carcasses were greater and those in EMA or in BF were smaller. In steer carcasses, price change by unit change in BF was greater than the other sex categories or all sex categories. In bull carcasses, unit price change per unit change in BF was positive, which supports the evidence of low average quality grade and the importance of feeding bulls to a targeted quality grade based on the price of beef. As relative economic weights are only of importance to breeding farms rather than their absolute values in various profit criteria (Moav, 1973; Weller, 1994), partial regression coefficients estimated by Kim et al. (2010) were close to the results from this study except that regression of carcass unit price (won $/ \mathrm{kg}$ ) on CW was -1.40 instead of positive value in our result. This might be because they (Kim et al., 2010) fit dressing percentage in addition to the model with four traits in our model. Dressing percentage in itself is composed of $\mathrm{CW}$ ratio to live animal weight such that higher dressing percentage implies less weight of internal organs including disposable abdominal fat in proportion to $\mathrm{CW}$. Ibi et al. (2006) and Kahi et al. (2007) estimated economic weights of carcass traits on Japanese beef cattle populations. In Japanese Black (Ibi et al., 2006) or in Japanese Brown (Kahi et al., 2007) high economic emphasis on MS or BF was also obvious. Additional economic importance in the case of Japanese beef cattle was put on rib thickness, the weight of which was positive in terms of carcass unit price. The difference in their estimation and our results implies a different beef market structure but similar consumers' preferences in beef quality.

Figure 1 shows various diagnostic statistics of the models and data structure fit to estimate parameters in Table 4 only in the case of all sex categories. Variation appears normal but there seems to be some outliers still especially around high price values.

\section{CONCLUSION}

Economic weights for carcass traits in Hanwoo

Table 4. Parameter estimates from different models (dependent variable: price/kg carcass)

\begin{tabular}{|c|c|c|c|c|c|c|c|c|c|c|}
\hline \multirow{3}{*}{$\begin{array}{l}\text { Effects } \\
\text { and } \\
\text { covariates }^{1}\end{array}$} & \multirow{2}{*}{\multicolumn{3}{|c|}{ All sexes }} & \multicolumn{7}{|c|}{ Sex categories } \\
\hline & & & & \multicolumn{3}{|c|}{ Female } & \multicolumn{2}{|l|}{ Bull } & \multicolumn{2}{|l|}{ Steer } \\
\hline & df & Estimate $\pm \mathrm{SE}$ & $\begin{array}{c}\mathrm{wt}^{3} \\
\text { std wt* }\end{array}$ & df & Estimate $\pm \mathrm{SE}$ & wt $\%$ & Estimate $\pm \mathrm{SE}$ & wt $\%$ & Estimate $\pm \mathrm{SE}$ & wt $\%$ \\
\hline $\bar{N}\left(\mathrm{R}^{2}\right)$ & & $476,430(0.62)$ & & & $195,040(0.55)$ & & $38,262(0.25)$ & & $243,129(0.58)$ & \\
\hline Sex $\times$ house $^{2}$ & 38 & $-1,067.86$ & & & & & & & & \\
\hline House & & & & 12 & -755.95 & & $1,304.95$ & & -158.61 & \\
\hline Intercept & & $\begin{array}{r}7,701.74 \\
\pm 90.45\end{array}$ & & & $\begin{array}{r}4,654.14 \\
\pm 90.20\end{array}$ & & $\begin{array}{r}5,687.67 \\
\pm 395.26\end{array}$ & & $\begin{array}{r}10,473.20 \\
\pm 73.53\end{array}$ & \\
\hline MS & 1 & $\begin{array}{r}948.52 \\
\pm 1.62\end{array}$ & $\begin{array}{l}129.9 \\
4(2,115.2)^{*}\end{array}$ & & $\begin{array}{r}1,086.56 \\
\pm 2.07\end{array}$ & 62.1 & $\begin{array}{r}1,363.13 \\
\pm 16.09\end{array}$ & 459.0 & $\begin{array}{r}822.52 \\
\pm 1.69\end{array}$ & 393.6 \\
\hline EMA & 1 & $\begin{array}{l}27.32 \\
\pm 0.37\end{array}$ & $\begin{array}{l}3.7 \\
1(334.1) *\end{array}$ & & $\begin{array}{l}16.91 \\
\pm 0.68\end{array}$ & 1.0 & $\begin{array}{l}16.94 \\
\pm 1.38\end{array}$ & 5.7 & $\begin{array}{l}27.94 \\
\pm 0.41\end{array}$ & 13.4 \\
\hline $\mathrm{BF}$ & 1 & $\begin{array}{r}-95.18 \\
\pm 0.61\end{array}$ & $\begin{array}{l}-13.0 \\
-1(-558.7) *\end{array}$ & & $\begin{array}{r}-96.92 \\
\pm 1.01\end{array}$ & -5.5 & $\begin{array}{l}21.86 \\
\pm 4.57\end{array}$ & 7.4 & $\begin{array}{r}-105.02 \\
\pm 0.68\end{array}$ & -50.2 \\
\hline $\mathrm{CW}$ & 1 & $\begin{array}{r}7.30 \\
\pm 0.09\end{array}$ & $\begin{array}{l}1.0 \\
1(492.9)^{*}\end{array}$ & & $\begin{array}{l}17.50 \\
\pm 0.18\end{array}$ & 1.0 & $\begin{array}{r}2.97 \\
\pm 0.31\end{array}$ & 1.0 & $\begin{array}{r}2.09 \\
\pm 0.09\end{array}$ & 1.0 \\
\hline
\end{tabular}

\footnotetext{
${ }^{1} \mathrm{MS}=$ Marbling score (1 to 9), EMA = Eye muscle area $\left(\mathrm{cm}^{2}\right), \mathrm{BF}=$ Backfat thickness (mm), CW = Carcass weight $(\mathrm{kg})$.

${ }^{2}$ house $=$ Abattoir. ${ }^{3}$ Weights relative to the estimates of carcass weight (increase in value, won, per unit increase in covariate).

* Weights when standardized values of carcass measures were taken into model fit(regression coefficients in the parentheses).
} 


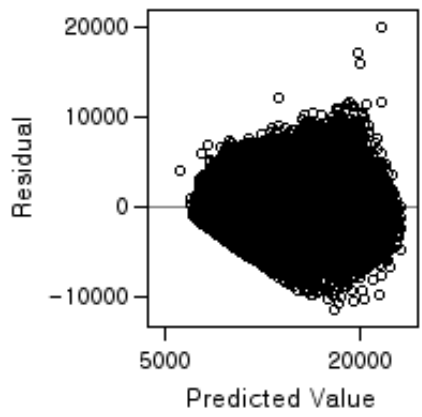

Fit Diagnostics for price
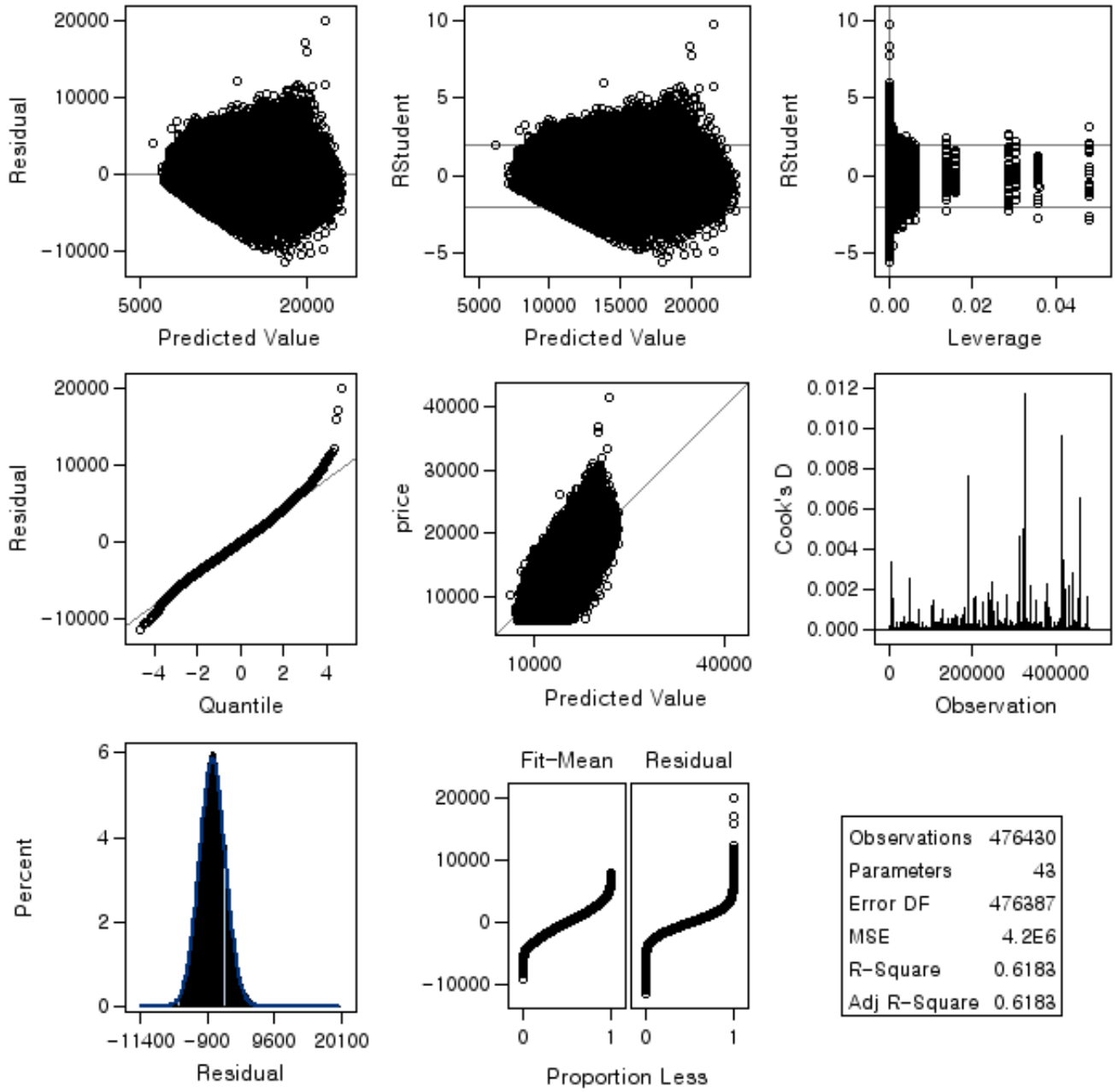

Figure 1. Fit diagnostics diagram for the model of all sexes (First model in Table 3).

population in Korea were estimated in terms of relative weights per $\mathrm{kg}$ carcass production. Due to a high demand for quality grades in the Korean beef market, most emphasis was put on marbling score. The second most pressure was on backfat thickness, which is the strongest determinant of carcass yield grade. These weights were different in bull carcasses representing different feeding systems by sex categories. Female carcasses are a big portion of the Korean beef market next to that of steers. Further research work should be undertaken on this carcass price to determine the relative economic weight to be placed at the level of the whole animal basis and the cost structure of management styles by different sex categories.

\section{ACKNOWLEDGEMENT}

Authors appreciate the endeavor collecting carcass data by the members of the Korean Institute for Animal Products Quality Evaluation (KAPE) and their kind cooperation in making possible this research work. This project was fully funded by "Cooperative Research Program for Agriculture
Science \& Technology Development" of Rural Development Administration, Republic of Korea (project no: PJ906937).

\section{REFERENCES}

Baik, D. H., M. A. Hoque, G. H. Park, H. K. Park, K. S. Shim and Y. H. Chung. 2003. Heritabilities and genetic correlation, and sire and environment effects on meat production potential of Hanwoo cattle. Asian-Aust. J. Anim. Sci. 16:1-5.

Choy, Y. H., C. W. Lee, H. C. Kim, S. B. Choi, J. K. Choi and J. M. Hwang. 2008. Genetic models for carcass traits with different slaughter endpoints in selected Hanwoo herds I. Linear covariance models. Asian-Aust. J. Anim. Sci. 21:1227-1232.

Choy, Y. H., S. B. Choi, G. J. Jeon, H. C. Kim, H. J. Chung, J. M. Lee, B. Y. Park and S. H. Lee. 2010. Prediction of retail beef yield using parameters based on Korean beef carcass grading standards. Korean J. Food Sci. Anim. Resour. 30:905-909.

Ibi, T., A. K. Kahi and H. Hirooka. 2006. Effect of carcass price fluctuations on genetic and economic evaluation of carcass traits in Japanese Black cattle. J. Anim. Sci. 84:3204-3211.

Johnson, R. A. and D. W. Wichern. 1992. Applied multivariate 
statistical analyses. Prentice-Hall, Inc. Englewood Cliffs, NJ, Moav, R. 1973. Economic evaluation of genetic differences. In: USA.

Kahi, A. K., T. Oguni, Y. Sumio and H. Hirooka. 2007. Genetic relationships between growth and carcass traits and profitability in Japanese Brown cattle. J. Anim. Sci. 85:348355.

Kim, D. J., C. W. Lee, C. Y. Lee and J. B. Kim. 2010. The influence of carcass traits on carcass price in mature Hanwoo cow. J. Anim. Sci. Technol. 52:157-164 (in Korean). Agricultural Genetics, Selected Topics (Ed. R. Moav). John Wiley and Sons. New York, NY, USA. pp. 319-352.

Perez-Cabal, M. A. and R. Alenda. 2002. Genetic relationships between lifetime profit and type traits in Spanish Holstein cows. J. Dairy Sci. 85:3480-3491.

Perez-Cabal, M. A. and R. Alenda. 2003. Lifetime profit as an individual trait and prediction of its breeding values in Spanish Holstein cows. J. Dairy Sci. 86:4115-4122.

Lee, J. W., S. B. Choi, J. S. Kim, J. F. Keown and L. D. Van Vleck. 2000. Parameter estimates for genetic effects on carcass traits of Korean Native cattle. J. Anim. Sci. 78:1181-1190.

SAS/STAT ${ }^{\circledR} 9.22$ User's Guide. 2010. SAS Institute Inc. Cary, NC, USA.

Visscher, P. M. and M. E. Goddard. 1995. Genetic analyses of profit for Australian dairy cattle. Anim. Sci. 61:9-18.

Weller, J. I. 1994. Economic aspects of animal breeding. Chapman \& Hall. London, UK. 